\title{
Thermo-Mechanical Effect on Poly Crystalline Boron Nitride Tool Life During Friction Stir Welding (Dwell Period)
}

\author{
M. Almoussawi ${ }^{1,2}$. A. J. Smith ${ }^{2}$
}

Received: 18 August 2017 / Accepted: 22 November 2017 / Published online: 20 March 2018

(c) The Author(s) 2018

\begin{abstract}
Poly Crystalline Boron Nitride (PCBN) tool wear during the friction stir welding of high melting alloys is an obstacle to commercialize the process. This work simulates the friction stir welding process and tool wear during the plunge/dwell period of $14.8 \mathrm{~mm}$ EH46 thick plate steel. The Computational Fluid Dynamic (CFD) model was used for simulation and the wear of the tool is estimated from temperatures and shear stress profile on the tool surface. Two sets of tool rotational speeds were applied including 120 and 200 RPM. Seven plunge/dwell samples were prepared using PCBN FSW tool, six thermocouples were also embedded around each plunge/dwell case in order to record the temperatures during the welding process. Infinite focus microscopy technique was used to create macrographs for each case. The CFD result has been shown that a shear layer around the tool shoulder and probe-side denoted as thermo-mechanical affected zone (TMAZ) was formed and its size increase with tool rotational speed increase. Maximum peak temperature was also found to increase with tool rotational speed increase. PCBN tool wear under shoulder was found to increase with tool rotational speed increase as a result of tool's binder softening after reaching to a peak temperature exceeds $1250{ }^{\circ} \mathrm{C}$. Tool wear also found to increase at probe-side bottom as a result of high shear stress associated with the decrease in the tool rotational speed. The amount of BN particles revealed by SEM in the TMAZ were compared with the CFD model.
\end{abstract}

Keywords PCBN tool $\cdot$ Wear $\cdot$ Friction stir welding $\cdot$ EH46 steel

\section{Introduction}

Friction Stir Welding (FSW) which invented at TWI company in 1991 is still limited to low melting alloys due to the tool cost. The process was mainly applied to overtake the issues of porosity and microstructure solidification associated with fusion welding of aluminium alloys such as 2XXX and 7XXX series which represented for long time as un-weldable alloys [1]. In FSW of low melting alloys such as aluminium, steel tool such as H13 is adequate for completing the welding process without noticeable wear issues. However, for welding high melting alloys such as steel grades, FSW tool materials should have high thermal and mechanical properties in order to cope with the wear issues. Poly Crystalline Boron Nitride (PCBN) is one example of

\footnotetext{
M. Almoussawi

acesma4@exchange.shu.ac.uk; inj.mun@atu.edu.iq

1 Al-Furat Al-Awsat University, Kufa, Iraq

2 MERI, Sheffield Hallam University, Sheffield S1 1WB, UK
}

these tools which is widely used for joining the high melting alloys such as carbon steel, stainless steel and Ti alloys. Table 1 [2] shows the mechanical and thermal properties of this tool compared to tungsten carbide WC and H13 FSW tools. The micro hardness of this tool HV (2600-3500) shows that the PCBN tool is the second hardest tool after diamond. It also has a low coefficient of friction which in turn helps in producing smooth surfaces after completing the FSW process [3]. However, a low coefficient of friction in a FSW tool necessitates the increase in tool rotational speed to produce the required heat for welding [4]. Different types of PCBN tools have been produced by MegaStir in the recent years including Q60 (60\% PCBN, 40\% WRe) and Q70 (70\% PCBN, 30\% WRe) [5]. The melting point of Q70 tool which is under concern in this work has determined to exceed $3000{ }^{\circ} \mathrm{C}$, the microstructure and tool image are shown in Fig. 1a, b respectively [5]. The PCBN-WRe Q70 tool as shown in Fig. 1b mainly consists of shoulder and probe which surrounded by an insulator collar made of $\mathrm{Ni}-\mathrm{Cr}$ works as a holder to the tool and also to connect the tool to the PowerStir ${ }^{\mathrm{TM}}$ FSW machine. The temperature 
Table 1 The physical properties of PCBN compared with few other materials [2]
Fig. 1 a SEM image of PCBN Q70 (70\% cBN, 30\% WRe) [6], b PCBN tool image

\begin{tabular}{lllll}
\hline Property & Units & PCBN & Tungsten carbide & 4340 steel \\
\hline Coefficient of friction & - & $0.10-0.15$ & 0.2 & 0.78 \\
Coefficient of thermal expansion & $10^{-6} /{ }^{\circ} \mathrm{C}$ & $4.6-4.9$ & $4.9-5.1$ & $11.2-14.3$ \\
Thermal conductivity & $\mathrm{W} / \mathrm{mk}$ & $100-250$ & 95 & 48 \\
Compressive strength & $\mathrm{N} / \mathrm{mm}^{2}$ & $2700-3500$ & 6200 & 690 \\
& $10^{3} \mathrm{psi}^{2}$ & $391-507$ & 899 & 100 \\
Fracture toughness & $\mathrm{Mpa} \mathrm{\textrm {m } ^ { 2 }}$ & $3.5-6.7$ & 11 & 100 \\
Hardness & $\mathrm{Knoop} \mathrm{kg} / \mathrm{mm}^{2}$ & $2700-3200$ & - & 278 \\
& vickers kg/mm $\mathrm{mm}^{2}$ & $2600-3500$ & $1300-1600$ & 280 \\
Tensile strength & $\mathrm{N} / \mathrm{mm}^{2}$ & - & 1100 & 620 \\
& $10^{3} \mathrm{psi}$ & - & 160 & 89.9 \\
Transverse rupture strength & $\mathrm{N} / \mathrm{mm}^{2}$ & $500-800$ & 2200 & - \\
& $10^{3} \mathrm{psi}^{2}$ & & 319 & - \\
\hline
\end{tabular}

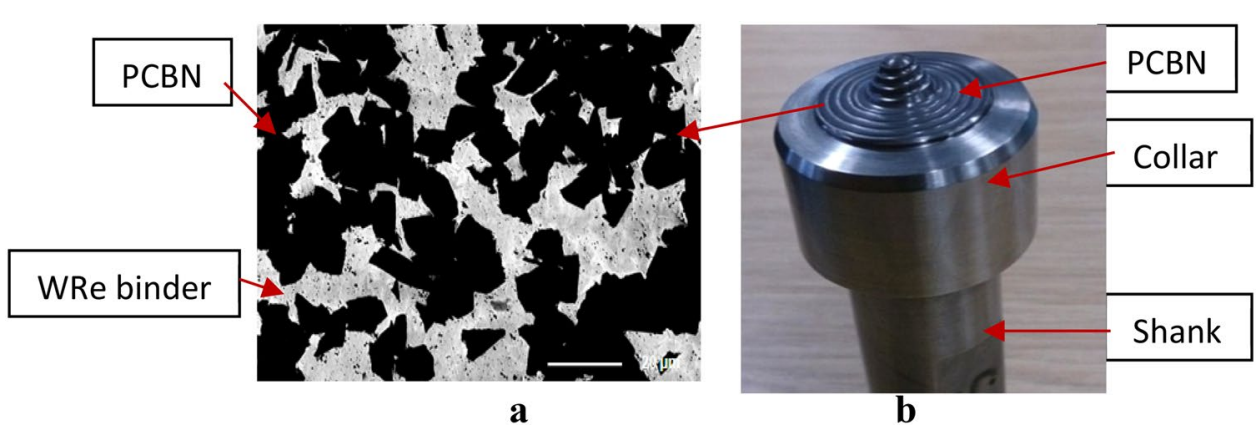

of the tool measured by telemetry thermocouples system attached to the PCBN part have to be in the range of $800-900{ }^{\circ} \mathrm{C}$ in order to protect the tool from wear/breakage issues as recommended by the manufacturer [6]. This paper is focus only on the PCBN tool wear as this is the tool which has been used to produce the samples under study. Other tool materials which have been used for high melting alloys are usually made of refractory materials based on tungsten such as WC, W-Re, W-Co and can be found in literatures [3-7].

Wear issues in PCBN FSW tool considered better than other refractory materials such as tungsten based tools. $\mathrm{W}-25 \%$ Re FSW tool life of $4 \mathrm{~m}$ was reported in welding steel grades and titanium [7]. Softening of W-Re binder in the PCBN FSW tool was determined as the main source of the reduction in the tool wear resistance. Ramalingam and Jacobson [8] reported a decrease in Knoop hardness (HK) of W-25 Re from HK 675 (HV 638) to HK 500 (478) when carrying out heating from room temperature to $1225^{\circ} \mathrm{C}$. The hardness was found to decrease dramatically to HK 300 (HV 290) when the temperature increases to $1450{ }^{\circ} \mathrm{C}$ [9]. Park et al. 2009 investigated the wear of PCBN FSW tool and its effect on the formation of the second phases in two types of stainless steel grades. They found that the stirred zone (SZ) of the austenitic stainless steel, the nitrogen content coming from the PCBN tool is higher than in the ferritic stainless steel. The higher tool wear in austenitic stainless steel was attributed to the higher flow stress which was about 1.5 times higher than the ferritic stainless steel. They also found that $\mathrm{Cr}$ has reacted with $\mathrm{B}$ to form borides in a form of $\mathrm{Cr}_{2} \mathrm{~B}$ and $\mathrm{Cr}_{5} \mathrm{~B}_{3}$ [10]. Parker et al. 2003 reported the issues of using PCBN tool during FSW process of steel and stainless steel and found that the unsuitable rotational speeds can cause either a brittle breakage or thermal wear [11]. Zhang et al. 2012 classified the PCBN tool wear into two types: adhesive wear at low tool rotational speeds and abrasive wear at high tool rotational speed [12]. Kim et al. 2014 investigated the wear of PCBN tool by revealing the borides compounds in the TMAZ using the secondary ion mass spectroscopy (SIMS) technique. They found that a combination of clusterpolyatomic ion of ${ }^{11} \mathrm{~B}^{16} \mathrm{O}^{2}$ and ${ }^{56} \mathrm{Fe}^{16} \mathrm{O}$ was mainly formed in the TMAZ during the FSW process [13]. Miles et al. 2013 compared the tool wear of two grades of PCBN FSW tool including Q60 (60\% PCBN and 40\% W-Re) and Q70 (70\% PCBN and 30\% W-Re) during welding $1.4 \mathrm{~mm} \mathrm{DP}$ 980 steel. By the aid of lap shear testing technique, PCBN Q70 FSW tool has showed better wear resistance and also improved joint strength. Numerical technique based on CFD and Archard equation has been used in order to evaluate the wear of WRe-HfC tool during FSW of $6 \mathrm{~mm} 304$ stainless steel [14]. Maximum tool wear was found on the shoulder periphery and attributed to the rapid change in flow. The combined flow of shoulder/probe was found to cause 
Table 2 PCBN tool geometry provided by TWI

\begin{tabular}{|c|c|c|c|c|}
\hline Tool & PCBN shoulder & PCBN probe & Collar & Shank \\
\hline $\begin{array}{l}\text { PCBN for welding } \\
10-15 \mathrm{~mm} \text { thickness }\end{array}$ & $\begin{array}{l}38 \mathrm{~mm} \text { mm diameter with } \\
\text { spiral convex shape }\end{array}$ & $\begin{array}{l}12 \text { mm length, } 20 \mathrm{~mm} \text { base } \\
\text { diameter spiral tapered } \\
\text { with } 20 \text { thread per inch } \\
\text { (TPI) }\end{array}$ & $\begin{array}{l}38.1 \mathrm{~mm} \text { inner diameter } \\
52 \mathrm{~mm} \text { outer diameter } \\
30 \mathrm{~mm} \text { length }\end{array}$ & $\begin{array}{l}38.1 \mathrm{~mm} \text { Diameter } 100 \mathrm{~mm} \\
\text { length }\end{array}$ \\
\hline
\end{tabular}

Table 3 Chemical composition (wt\%) of EH46 steel grade

\begin{tabular}{llllllllll}
\hline $\mathrm{C}$ & $\mathrm{Si}$ & $\mathrm{Mn}$ & $\mathrm{P}$ & $\mathrm{S}$ & $\mathrm{Al}$ & $\mathrm{N}$ & $\mathrm{Nb}$ & $\mathrm{V}$ & $\mathrm{Ti}$ \\
\hline 0.20 & 0.55 & 1.7 & 0.03 & 0.03 & 0.015 & 0.02 & 0.03 & 0.1 & 0.02 \\
\hline
\end{tabular}

an increase in the pressure at the mid axial position of the probe which in turn has led to a high wear at this part of the tool [14].

The current work focuses on the PCBN tool wear which occurs during FSW (plunge/dwell) process of EH46 steel grade. CFD modelling was employed to simulate the process and to assess the possible wear on the tool surface depending on the temperature and shear stress profile on the tool surface without using additional equations such as modified Archard equation [14]. The current work also represents the combination between simulation and experiments which aims mainly to increase the PCBN tool longevity without doing many trails and error experiments.

\section{Materials and Method}

\subsection{Workpiece Material and Welding Conditions}

The FSW tool used to produce the samples is a hybrid PCBN-WRe which consist of a shoulder (diameter $38 \mathrm{~mm}$ ) and probe (length $12 \mathrm{~mm}$ ). The parts of PCBN FSW tool and dimension which provided by TWI are listed in Table 2 . The parent material used in the welding trials was $14.8 \mathrm{~mm}$ thick EH46 steel plate; the chemical composition is shown in Table 3.

The position of the individual weld plunges and the six thermocouples were carefully mapped in order to increase the accuracy of temperature measurements. Seven weld plunge trials were carried out at TWI/Yorkshire using the PowerStir FSW machine as shown in Fig. 2. The plunge trail welds are numbered as W1-W7 as shown in Table 4 which includes the details of different welding parameters, the peak temperatures of TCs are listed in Table 5.

Thermocouples (TCs) were inserted in blind holes $(1 \mathrm{~mm}$ depth) inside the plates and fixed firmly at $29 \mathrm{~mm}$ away from the tool center of the EH46 plunge trials as shown in Fig. 3.

Table 5 shows the peak temperatures measured by the thermocouples for each welding trial.

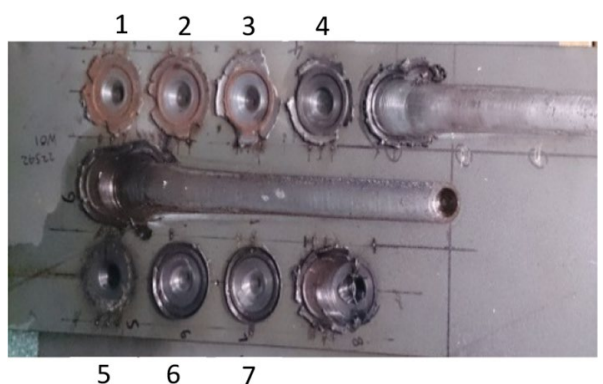

Fig. 2 EH46 steel plate showing the position of the seven plunge trials

Some thermo-couple data is missing because it either has been displaced by the FSW flash or it did not record the temperature.

\subsection{Sample Preparation for Infinite Focus Microscope (IFM)}

The Infinite Focus Microscopy (IFM) has been used to accurately measure the depth of each plunge hole before cutting the samples into two halves. Each of the plunge cavities were cut into two halves in the direction perpendicular to the thermocouple location as shown in Fig. 3 (line of cutting). Samples were then polished to 1 micron and etched by $2 \%$ Nital to reveal the affected zones.

\subsection{SEM and EDX}

Scanning electron microscopy and X-ray energy dispersive examinations were carried out on the polished and etched samples for each plunge/dwell trial in order to detect the presence of BN in the thermo-mechanical affected zones (TMAZ). BN coming from the PCBN FSW tool in the TMAZ of the welded joints were calculated by the aid of SEM scanning. The fraction volume of $\mathrm{BN}$ particles have been measured manually using a square grid. The number of intersections of the grid 
Table 4 The welding conditions of FSW EH46 plunge/dwell period (W1-W7)

\begin{tabular}{lllllll}
\hline Weld trial No. & $\begin{array}{l}\text { Tool rotational speed } \omega \\
(\mathrm{RPM}) \text { at dwell period }\end{array}$ & $\begin{array}{l}\text { Max. Axial } \\
\left(\text { Plunge force }\left(\mathrm{F}_{\mathrm{z}}\right)\right. \\
\text { KN }\end{array}$ & $\begin{array}{l}\text { Max. Longitudi- } \\
\text { nal force }\left(\mathrm{F}_{\mathrm{x}}\right) \mathrm{KN}\end{array}$ & $\begin{array}{l}\text { Max. Torque } \\
(\mathrm{M}) \mathrm{N} \mathrm{m}\end{array}$ & $\begin{array}{l}\text { Plunge depth }(\mathrm{Z}) \mathrm{mm} \\
\text { from FSW machine }\end{array}$ & $\begin{array}{l}\text { Dwell time }(\mathrm{t}) \text { sec } \\
\text { at }(\mathrm{dwell}) \text { period }\end{array}$ \\
\hline W1 & 200 & 157 & 17 & 498 & 13 & 6 \\
W2 & 200 & 127 & 17 & 471 & 13 & 8 \\
W3 & 120 & 116 & 21 & 598 & 13 & 7 \\
W4 & 120 & 126 & 20 & 549 & 13 & 7 \\
W5 & 120 & 115 & 17 & 532 & 13 & 7 \\
W6 & 120 & 105 & 18 & 583 & 13 & 7 \\
W7 & 120 & 119 & 20 & 548 & 13 & 7 \\
\hline
\end{tabular}

Table 5 Thermocouples measurements of the seven plunge trials

\begin{tabular}{|c|c|c|c|c|c|c|}
\hline Weld No. & $\begin{array}{l}\text { Maximum recorded } \\
\text { temp. } \mathrm{T}^{\circ} \mathrm{C} \mathrm{TC} 1\end{array}$ & $\begin{array}{l}\text { Maximum recorded } \\
\text { temp. T }{ }^{\circ} \mathrm{C} \text { TC } 2\end{array}$ & $\begin{array}{l}\text { Maximum recorded } \\
\text { temp. T }{ }^{\circ} \mathrm{C} \text { TC } 3\end{array}$ & $\begin{array}{l}\text { Maximum recorded } \\
\text { temp. T }{ }^{\circ} \mathrm{C} \text { TC } 4\end{array}$ & $\begin{array}{l}\text { Maximum recorded } \\
\text { temp. T }{ }^{\circ} \mathrm{C} \text { TC5 }\end{array}$ & $\begin{array}{l}\text { Maximum } \\
\text { recorded temp. } \\
\mathrm{T}{ }^{\circ} \mathrm{C} \text { TC6 }\end{array}$ \\
\hline W1 & 430 & 630 & 430 & 422 & 600 & 421 \\
\hline W2 & 444 & 650 & - & 427 & 620 & 432 \\
\hline W3 & 380 & 550 & 381 & 382 & 545 & - \\
\hline W4 & 400 & 580 & - & 402 & 581 & 405 \\
\hline W5 & - & 544 & 375 & 380 & 553 & 381 \\
\hline W6 & - & - & 420 & 410 & - & - \\
\hline W7 & 400 & 554 & - & - & - & - \\
\hline
\end{tabular}

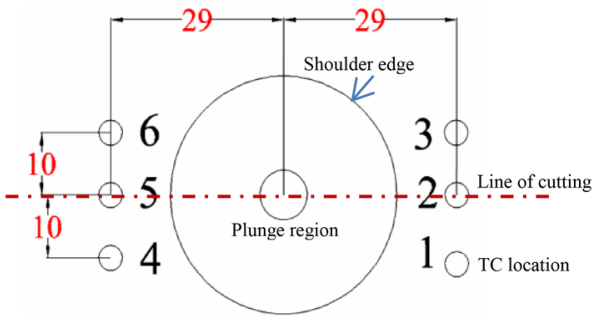

Fig. 3 Thermocouples locations around each plunge trial

falling in the BN particles are counted and compared with the total number of points laid down.

\subsection{Numerical Analysis}

\subsubsection{CFD Numerical Analysis Equations}

The model created in this study uses CFD analysis and includes solving equations of momentum, mass and energy. Viscosity is also included in the model as a function of temperature and strain rate.

The continuity equation for incompressible material can be represented as [15] $\frac{\partial u_{i}}{\partial x_{i}}=0$

$u_{i}$ is the velocity of plastic flow in index notation for $i=1,2$ and 3 which represent the Cartesian coordinate of $\mathrm{x}, \mathrm{y}$ and $\mathrm{z}$ respectively.

The temperature and velocity field were solved assuming steady state behaviour. The plastic flow in a three dimensional Cartesian coordinates system can be represented by the momentum conservation equation in index notation with $\mathrm{i}$ and $\mathrm{j}=1,2$ and 3 , representing $\mathrm{x}, \mathrm{y}$ and $\mathrm{z}$ respectively [14]

$\rho \frac{\partial u_{i} u_{j}}{\partial x_{i}}=-\frac{\partial p}{\partial x_{j}}+\frac{\partial}{\partial x_{i}}\left(\mu_{u} \frac{\partial u_{j}}{\partial x_{i}}+\mu_{u} \frac{\partial u_{i}}{\partial x_{j}}\right)-\rho U \frac{\partial u_{j}}{\partial x_{1}}$

where $\rho, \mathrm{p}, \mathrm{U}$ and $\mu_{u}$ are density, pressure, welding velocity (which is zero in the case of plunge/dwell), and NonNewtonian viscosity, respectively. Viscosity is determined using the flow stress $\left(\sigma_{f}\right)$ and the effective strain rate $(\dot{\varepsilon})$ as follows [15]:

$\mu_{u}=\frac{\sigma_{f}}{3 \varepsilon}$. 
The flow stress in a perfect plastic model, proposed by Sheppard and Wright [15] can be represented as:

$\sigma_{f}=\frac{1}{\alpha} \sinh ^{-1}\left[\left(\frac{Z_{n}}{A i}\right)^{\frac{1}{n}}\right]$

n, $A i, \alpha$, are material constants. Previous work on $\mathrm{C}-\mathrm{Mn}$ steel showed that the parameter $A i$ can be written as a function of carbon percentage $(\% \mathrm{C})$ as follow [15]:

$A_{i}=1.8 \times 10^{6}+1.74 \times 10^{8}(\% C)-6.5 \times 10^{8}(\% C)^{2}$

$\alpha$ and $n$ are temperature dependants and can be represented as:

$\alpha=1.07+1.7 \times 10^{-4} T-2.81 \times 10^{-7} \mathrm{~T}^{2}$

$n=0.2+3.966 \times 10^{-4} \mathrm{~T}$

$\mathrm{Z}_{\mathrm{n}}$ is the Zener-Hollomon parameter which represents the temperature compensated effective strain rate as [12]:

$Z_{n}=\varepsilon \cdot \exp \left(\frac{Q e}{R T}\right)=A i\left[\sinh \alpha \sigma_{f}\right]^{n}$

$Q e$ is the activation energy, $R$ is the gas constant.

The effective strain rate can be represented as [15]:

$\varepsilon=\sqrt{\frac{2}{3} \varepsilon_{i j} \varepsilon_{i j}}$

$\varepsilon_{i j}$ is the strain tensor and can be represented as [15]:

$\varepsilon_{i j}=\frac{1}{2}\left(\frac{\partial u_{j}}{\partial x_{i}}+\frac{\partial u_{i}}{\partial x_{j}}\right)$.

Heat equation in a Eulerian frame work can be represented as [16]:

$\rho C_{p} \nabla(u T)=\nabla(k \nabla T)-\rho C_{p} v_{x} \frac{\partial T}{\partial x}+Q_{i}+Q_{b}$

$\rho$ Material density $\mathrm{Kg} / \mathrm{m}^{3}, \mathrm{C}_{\mathrm{p}}$ Specific heat $\mathrm{J} / \mathrm{Kg} \mathrm{K}, v_{\mathrm{x}}$ Velocity $\mathrm{m} / \mathrm{s}$ in the $\mathrm{X}$-direction which is equal to zero in the plunge case, $\mathrm{T}$ temperature $(\mathrm{K})$ and $\mathrm{k}$ is the thermal conductivity W/m.K. $Q_{i}$ Heat generated at the tool/workpiece interface (W). $Q_{b}$ Heat generated due to plastic deformation away from the tool/workpiece interface (W).

\subsubsection{Heat Generation in Fully Sticking Conditions}

The heat generated in this model is based on viscosity dissipation and material flow which affected by the tool rotation, shear layers are formed as a result of this material flow. The viscous heating $\left(\mu_{u}\left(\nabla^{2} u\right)\right)$ was assumed to be the main source of heat generation in this work. Previous work by Schmidt et al. [17] and Atharifar et al.
[18] showed experimentally that sticking conditions are closer to the real contact situation between the tool and workpiece. Cox et al. [19] carried out a CFD model on FSW and assumed pure sticking conditions at the tool/ workpiece contact area.

\subsubsection{Geometry}

CAD model for the tool and workpiece has been created, the same tool parts (shoulder, probe side and probe end) and dimensions have been used to design the plate keyhole before assembling the whole parts where the tool is plunged into the workpiece as shown in Fig. 4.

\subsubsection{Geometry Mesh and Mesh Quality}

For the assembled parts of workpiece and the hybrid PCBN tool, meshing was applied in a way that nodes between two different parts are connected. Multiple parts connections have been achieved in ANSYS Design Modeller by converting different designed parts into one part using the function (Form new part). Patch confirming method has been used in order to control the growth and smoothness and to obtain an accurate surface meshing. Tetrahedrons assembly meshing has been employed to cope with the complex connection between the tool and workpiece. Minimum face sizing of $0.1 \mathrm{~mm}$ has been applied in the tool/workpiece contact region to obtain a very fine mesh and thus all the physical and non-linear properties can be captured. Coarser mesh (larger cell) has been represented elsewhere in the geometry where only the heat transfer occurs. To obtain a fine surface transition mesh on curved and normal angles, the advanced size function curvature has been employed with a growth rate of 1.1. The solution convergence and stability are highly dependent up on the mesh quality, unsuitable mesh can cause in an unexpected description for the model physics outputs. For checking mesh quality, several metrics have been addressed before proceeding to model boundary conditions. The most important metric mesh in which any deviation from the standard can significantly affect the numerical analysis are: Aspect ratio, Skewness and Orthogonal quality.

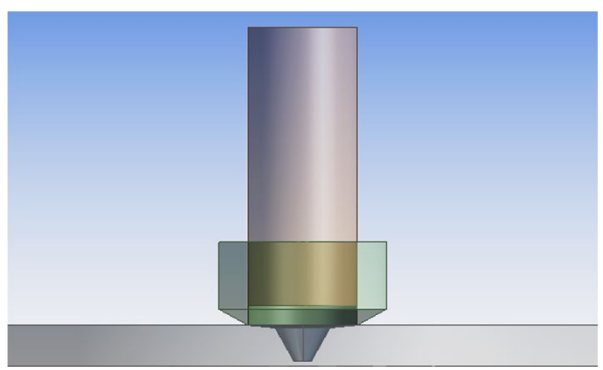

Fig. 4 Geometry of $14.8 \mathrm{~mm}$ EH46 and PCBN tool 


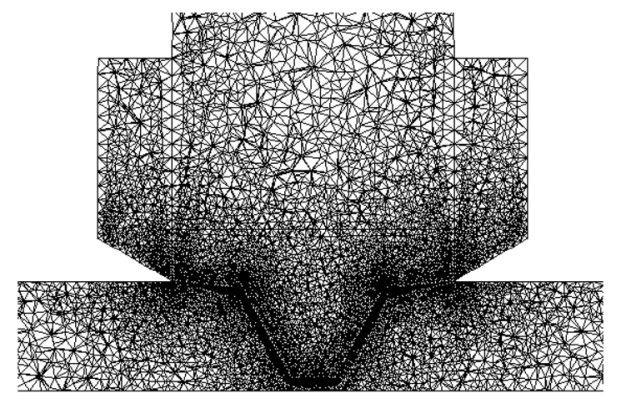

Fig. 5 Traverse section showing the mesh of $14.8 \mathrm{~mm}$ plate with PCBN FSW tool of $12 \mathrm{~mm}$ probe length, 3487,632 were used in $14.8 \mathrm{~mm}$ plate

Figure 5 shows traverse section of the mesh of $14.8 \mathrm{~mm}$ plate, the mesh is very fine at the tool/workpiece contact region. 3487,632 tetra elements were found to be the best refinement that can achieve the solution independence on mesh. The accepted standard range (very good) has been determined as shown in Table 6 [18].

\subsubsection{Boundary Conditions}

\section{Representing the Material Flow}

It is assumed theoretically that a specified node in the simulation shown in Fig. 6 as the tool rotates is transferred from location 1-2 and its coordinates may be represented as:

$X=r\left(\cos (\theta)-\cos \left(\theta_{o}\right)\right)$

$Y=r\left(\sin (\theta)-\sin \left(\theta_{o}\right)\right)$.

And by driving these coordinates equations the velocities $(\mathrm{u}, \mathrm{v})$ in $\mathrm{x}$ and $\mathrm{y}$ directions can be obtained as:

$u=\frac{d X}{d t}=r \omega \sin \theta$

$v=\frac{d Y}{d t}=r \omega \cos \theta$

Another velocity in the vertical $\mathrm{Z}$ direction may be represented as [21]:

$w=\phi \frac{R_{p} \omega}{2 \pi} \gamma$

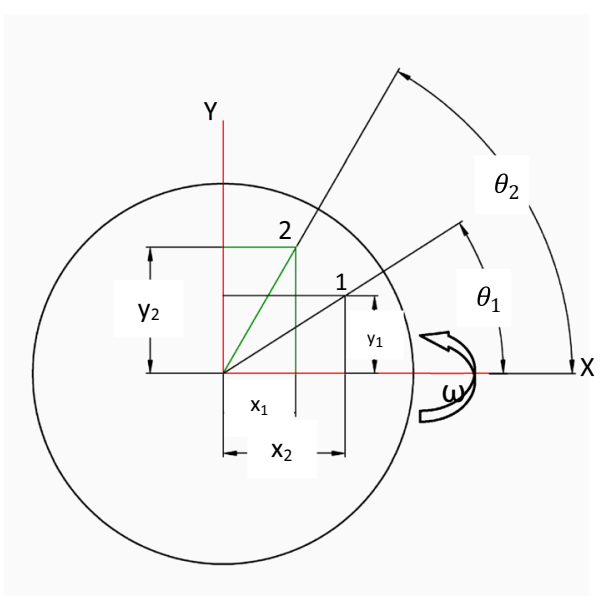

Fig. 6 The material flow around the tool (Dwell period), material is moved from point 1 to point 2

$\gamma R_{p}$ are the pitch and radius of the pin respectively. The total magnitude of the velocity as [21]:

$V=\sqrt{u^{2}+v^{2}+w^{2}}$.

Laminar flow has been chosen as the viscose forces are the most dominant during FSW process [22], viscous heating has been enabled during the solution.

II. Heat Transfer Between the Tool and Workpiece

The temperature of the workpiece was set to room temperature $\left(25^{\circ} \mathrm{C}\right)$. The heat loses from the tool-workpiece can be divided as.

A-Heat Fraction lost between the Tool and the Workpiece: Due to the low thermal conductivity of EH46 steel (as received from the manufacturer $=50 \mathrm{~W} / \mathrm{m}{ }^{\circ} \mathrm{C}$ ) compared to the tool types (PCBN) which is three times that of steel, the heat generated in the FSW process will be distributed between the tool and work piece.

Other researchers [21] [15] calculated this fraction $(f)$ as follows:

$f=\frac{J_{W P}}{J_{W P}+J_{T L}}=\frac{\sqrt{\left(k \rho C_{p}\right)_{W P}}}{\sqrt{\left(k \rho C_{p}\right)_{W P}}+\sqrt{\left(k \rho C_{p}\right)_{T L}}}$
Table 6 The standard of mesh metric and the "very good" accepted range [20]

\begin{tabular}{llllll}
\hline Mesh Metric & Min & Max & Average & SD & $\begin{array}{l}\text { Accepted Standard } \\
\text { range (Very Good) }\end{array}$ \\
\hline Aspect ratio & 1.1575 & 9.7184 & 1.8137 & 0.44382 & $5-10$ \\
Skewness & $1.0132 \mathrm{e}-008$ & 0.79981 & 0.21356 & 0.11432 & $0.25-0.5$ \\
Orthogonal quality & 0.24622 & 0.9979 & 0.86671 & $8.0851 \mathrm{e}-002$ & $0.6-0.95$ \\
\hline
\end{tabular}


$q=h\left(T-T_{o}\right)+\varepsilon \sigma\left(T^{4}-T_{o}\right)$

$f$ Heat fraction between the tool and workpiece, $\mathrm{k}$ : thermal conductivity in $(\mathrm{W} / \mathrm{m} \mathrm{K}), \rho$ :material density $\left(\mathrm{Kg} / \mathrm{m}^{3}\right), \mathrm{C}_{\mathrm{p}}$ specific heat $(\mathrm{J} / \mathrm{Kg} \mathrm{K}), \varepsilon$ emissivity of the plate surface, $\beta$ is Stefan-Boltzmann constant $\left(5.670373(21) \times 10^{-8} \mathrm{~W} \mathrm{~m}^{-2}\right.$ $\left.\mathrm{K}^{-4}\right)$. $\mathrm{T}_{\mathrm{o}}$ Initial temperature ${ }^{\circ} \mathrm{C} . \mathrm{h}$ thermal convection coefficient $\left(\mathrm{W} / \mathrm{m}^{2} \mathrm{~K}\right)$ The abbreviation wp and TL refer to the workpiece and the tool respectively.

So the heat transfer at the tool/shoulder interface is determined as follow:

$k \frac{\partial T}{\partial z}_{\text {top }}=\frac{\sqrt{\left(k \rho C_{p}\right)_{w p}}}{\sqrt{\left(k \rho C_{p}\right)_{w p}}+\sqrt{\left(k \rho C_{p}\right)_{T L}}} Q_{i}$.

The estimated heat fraction transformed into heat to the workpiece was determined between 0.4 and 0.45 for welding using a tungsten based tool and workpieces of stainless steel 304L [21]. However, for welding other types of steel such as EH46 using PCBN tool with a cooling system as in this work, Eq. 20 cannot accurately represent the heat fraction between tool and workpiece because:

1. The PCBN tool is a hybrid tool includes three types of material with different thermal properties (see Table 2)

2. The presence of the cooling system and gas shield will affect this heat fraction

Subrata and Phaniraj [23] agreed that Eq. 20 is only valid when the tool and plate are considered as infinite heat sink with no effects of heat flow from air boundary of the tool and they found that the heat partitioned to the tool is less than calculated from Eq. 20.

To solve this issue in modelling the FSW, the tool has been represented in the geometry in order to estimate the heat fraction numerically.

$B$. Heat removed from the tool shank during FSW process by the cooling system [24]

$Q_{\text {cooling }}=m^{o} C_{p} \Delta T$

$\mathrm{m}^{\mathrm{o}}$ is the flow rate of fluid (L/sec for liquid and $\mathrm{m}^{3} / \mathrm{sec}$ for gas).

The calculated heat has been divided on the exposed area and then represented on the tool shank as a negative heat flux. In previous work carried out on same materials (workpiece of DH36 and PCBN tool) [22] the cooling system was implemented under heat convection conditions on the side of the shank by applying a heat convection coefficient. Given that the maximum temperature on the tool cannot be measured with high precision, the calculated value of heat convection coefficient will not be accurate.
Hence, using a negative heat flux on the tool surface seems to be more convenient.

C-Heat Losses from Workpiece Surfaces (Top and Sides): Convection and radiation in heat transfer are responsible for heat loss $(Q)$ to the ambient and can be represented as [21]:

$Q=h A\left(T-T_{o}\right)+\varepsilon \beta A\left(T^{4}-T_{o}^{4}\right)$

$k \frac{\partial T}{\partial n}_{\Gamma}=q=h\left(T-T_{o}\right)+\varepsilon \beta\left(T^{4}-T_{o}^{4}\right)$

$T_{o}$-is the ambient temperature $\left(25^{\circ} \mathrm{C}\right), \mathrm{n}$ is the normal direction of boundary $\Gamma$.h is the convection coefficient $\left(\mathrm{W} \mathrm{m}^{-2} \mathrm{~K}\right.$ ${ }^{-1}$ ).

In the current model radiation does not take into consideration as it represents a small value and will add more complexity to the model. The value of heat transfer coefficient $(\mathrm{h})$ around the tool has been increased to compensate the effect of radiation [25].

D-Heat loss from Workpiece Bottom Surface: The lower surface of the plate is in contact with steel backing plates (usually mild and $\mathrm{O}_{1}$ steel grades) and the anvil. Previous workers [26] have suggested to represent the backing plates effects by a convection heat condition with a higher coefficient of heat transfer values $\left(500-2000 \mathrm{~W} / \mathrm{m}^{2} \mathrm{~K}\right)$. In the current model a value of $2000 \mathrm{~W} / \mathrm{m} \mathrm{K}$ has been used as it was found to give a suitable distribution for temperature at workpiece bottom.

E. The "Named Selection walls" surfaces and interior of the plate: The interior material of the plate was allowed to move by assigning an inlet velocity at one side. The other side of the plate was assigned with zero constant pressure to ensure there was no reverse flow at that side [14]. All plate walls were assumed to move with the same speed as the interior (no slip conditions) with zero shear stress at the walls. The normal velocity of the top and bottom of the plate was constrained to prevent outflow.

F. Gravitational Forces: Gravitational forces were neglected here due to the very high viscous effect of the material [18].

Figure 7 shows the boundary conditions applied on the tool and workpiece.

\subsubsection{CFD Solution Method}

A Pressure-based Navier-Stokes solution with pressure-velocity coupling [27] has been employed, this enables solving the problem in a coupled manner by obtaining a robust and effective single phase application for steadystate flows. Thus the pressure-based continuity (Eq. 1) and momentum (Eq. 2) equations are solved together. The spatial discretization including energy, momentum and pressure are solved using second order to increase the accuracy. 


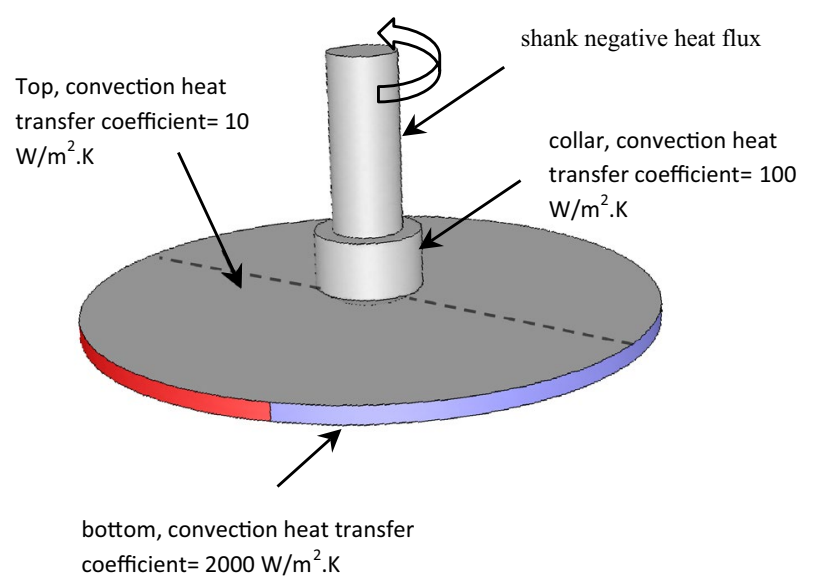

Fig. 7 The boundary conditions applied on the CFD modelling

Table 7 Thermal properties of the PCBN tool $[28,29]$

\begin{tabular}{|c|c|c|c|c|}
\hline Tool part & $\begin{array}{l}\mathrm{k} \\
\left(\mathrm{W} \mathrm{m} \mathrm{m}^{-1} \mathrm{~K}^{-1}\right)\end{array}$ & $\begin{array}{l}\mathrm{Cp} \\
\left(\mathrm{J} \mathrm{Kg}^{-1} \mathrm{~K}^{-1}\right)\end{array}$ & $\rho\left(\mathrm{Kg} \mathrm{m}^{-3}\right)$ & References \\
\hline $\begin{array}{l}\text { Shoulder } \\
\text { and probe } \\
\text { (PCBN- } \\
\text { WRe) }\end{array}$ & 120 & 750 & 3480 & [28] \\
\hline Shank (WC) & 92 & 500 & 14,900 & [28] \\
\hline Collar & 11 & 440 & 8900 & [29] \\
\hline
\end{tabular}

The model case analysis has been solved using the series procedure in order to override the problems of errors accompanied with the parallel solution and related to read and write files such as User Defined Function (UDF). The Double Precision solver has been chosen in order to increase the results accuracy. About $7 \mathrm{~h}$ were required to solve the case and obtaining the results.

\subsubsection{Materials Data Input for Modelling}

Thermal properties (density, specific heat and thermal conductivity) adopted from previous work carried out on low carbon manganese steel, are given as follows [28]:

$k=23.16+51.96 . e^{-2.03 T / 1000}$

$C p=689.2+46 \cdot 2 \cdot e^{3.78 T / 1000}$ for $\mathrm{T}<700{ }^{\circ} \mathrm{C}$

$C p=207.9+294 \cdot 4 \cdot e^{1.41 T / 1000}$ for $\mathrm{T}<700{ }^{\circ} \mathrm{C}$

$\rho=7850 \mathrm{Kg} / \mathrm{m}^{3}$ (Incompressible material)

where $\mathrm{k}, \mathrm{C}_{\mathrm{P}}$ and $\rho$ are thermal conductivity, the specific heat and density, respectively.
The thermal properties for the PCBN hybrid tool are given in Table 7 [29,30].

Tool parts have been treated to behave as solid while the workpiece as a fluid during the analysis. Thus a shadow surfaces "Walls" in the tool/workpiece have been created automatically with the thermal conditions chosen as "Coupled" to allow transferring the heat generated between the tool and workpiece. Tool properties have been input to the software as constants whereas, the workpiece properties as a function of temperature. The density of steel has been treated as constant, the thermal conductivity has been entered as a function of temperature by the aid of UDF, specific heat also was included as a function of temperature using piecewiselinear function and finally the viscosity was included as a function of temperature and strain rate by using UDF which represented in Eqs. 3-10.

\section{Results}

\subsection{Experimental Results}

The IFM scanning of W1-W7 are shown in Fig. 8 and Table 8, whereas SEM images of regions under shoulder of W2 and W6 are shown in Fig. 9 and Fig. 10 respectively. The SEM images of probe side bottom of W2 and W6 are shown in Fig. 11a, b respectively. Table 9 shows the calculated percentage $(\%)$ of $\mathrm{BN}$ at shoulder/probe side region, the scanned area was $1 \mathrm{~mm}^{2}$. Regions affected by the tool rotation as shown in Fig. 8 are Thermo-Mechanical Affected Zone (TMAZ), Inner Heat Affected Zone (IHAZ) and Outer Heat Affected Zone (OHAZ).

\subsection{CFD Results}

The CFD result of modelling the $14.8 \mathrm{~mm}$ EH46 at dwell period includes temperature distribution at the top surface of plate and in the normal direction are shown in Figs. 12 and 13 respectively. Temperatures recorded by TC2 and TC5 shown in Table 5 were compared to CFD data as shown in Fig. 14. Velocity, strain rate and viscosity were also listed in order to understand the thermo-mechanical effects of the PCBN tool on the material at the contact region as shown in Figs. 15, 16, 17 respectively. Tool temperatures and surface shear stress were shown in Figs. 18 and 19 respectively, these figures is to understand the possibility of thermal wear due to binder softening and the thermo-mechanical wear due to the increase in shear stresses. 


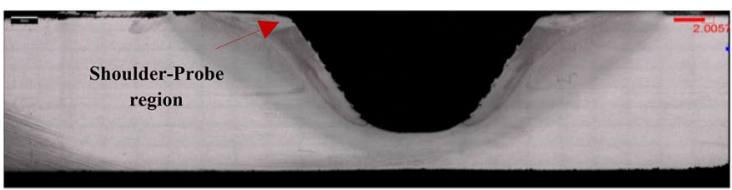

W1

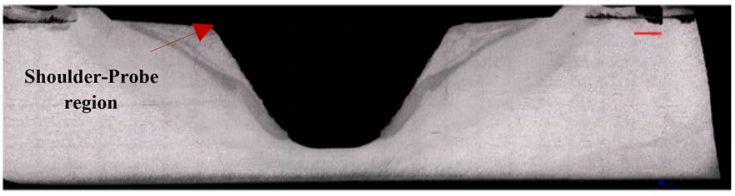

W3

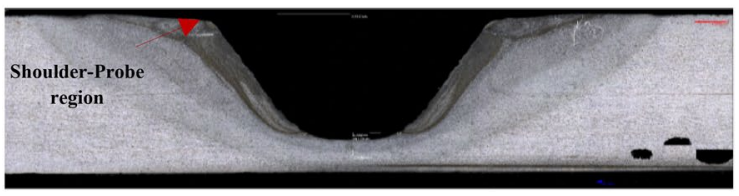

W5

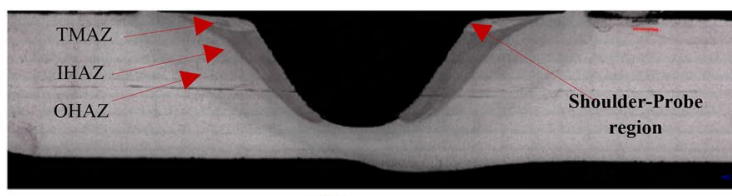

W2

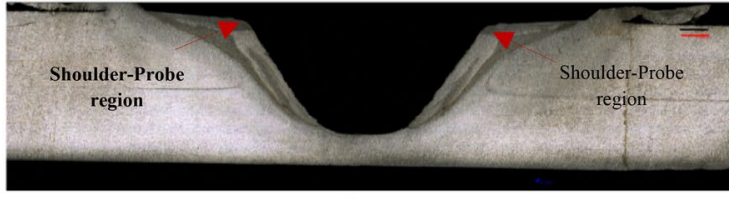

W4

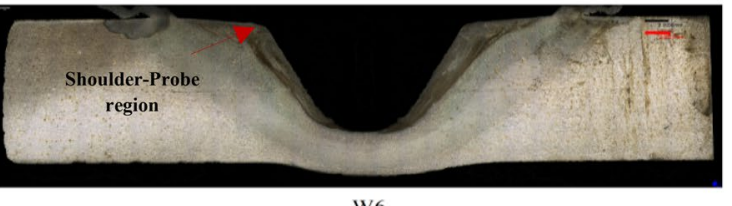

W6

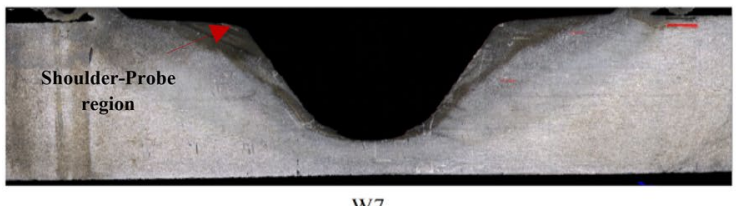

$\overline{2 m m}$

Fig. 8 Micrographs of longitudinal cross section taken from samples W1-W7, polished and etched by $2 \%$ Nital

Table 8 The IFM measurements of plunge depth and area of affected zones W1 to W7 EH46 steel

\begin{tabular}{lllll}
\hline Weld No. & $\begin{array}{l}\text { Plunge depth (Z) } \\
\text { mm (IFM) }\end{array}$ & $\begin{array}{l}\text { Total TMAZ (region 1+2) } \\
\text { area } \mathrm{mm}^{2}(\mathrm{IFM})\end{array}$ & $\begin{array}{l}\text { (Region 3) IHAZ } \\
\mathrm{mm}^{2}(\mathrm{IFM})\end{array}$ & $\begin{array}{l}\text { (Region 4) } \\
\text { OHAZ } \mathrm{mm}^{2} \\
\text { (IFM) }\end{array}$ \\
\hline W1 & 11.05 & 47.46 & 64.7 & 82 \\
W2 & 11.43 & 67.5 & 78.5 & 102 \\
W3 & 11.56 & 58 & 69.6 & 112.6 \\
W4 & 11.47 & 66 & 64.25 & 118 \\
W5 & 11.47 & 55 & 93.5 & 120.4 \\
W6 & 11.78 & 68 & 99.5 & 143.8 \\
W7 & 11.57 & 57.2 & 91 & 120 \\
\hline
\end{tabular}

\section{Discussion}

\subsection{Experimental}

Figure 8 shows the macrograph of W1-W7 which created by the aid of IFM technique, three regions affected by the tool have recognised and classified as thermo-mechanical affected zone TMAZ which is in direct contact with the FSW tool, inner heat affected zone IHAZ located directly after the TMAZ and outer heat affected zone OHAZ. The TMAZ which is under concern in this work was found to contain BN particles as revealed by the SEM images shown in Figs. 9, 10 and 11. This can give an indicate that this region has not only been experienced heating but also has been mechanically stirred (rotated around the tool). The maximum existence of $\mathrm{BN}$ particles was found in the region between shoulder and probe as assigned in Fig. 8, this can be attributed to the thermo-mechanical combination of both shoulder and probe. This thermo-mechanical combination has also resulted in a spiralling motion for the material as shown in Fig. 8. From Table 8; it can be shown that actual plunge depth measured by the IFM showed a difference from the one recorded by FSW machine (Table 4). This difference can be interpreted as a deflection in the FSW machine due to stiffness issues. According to this difference in plunge 


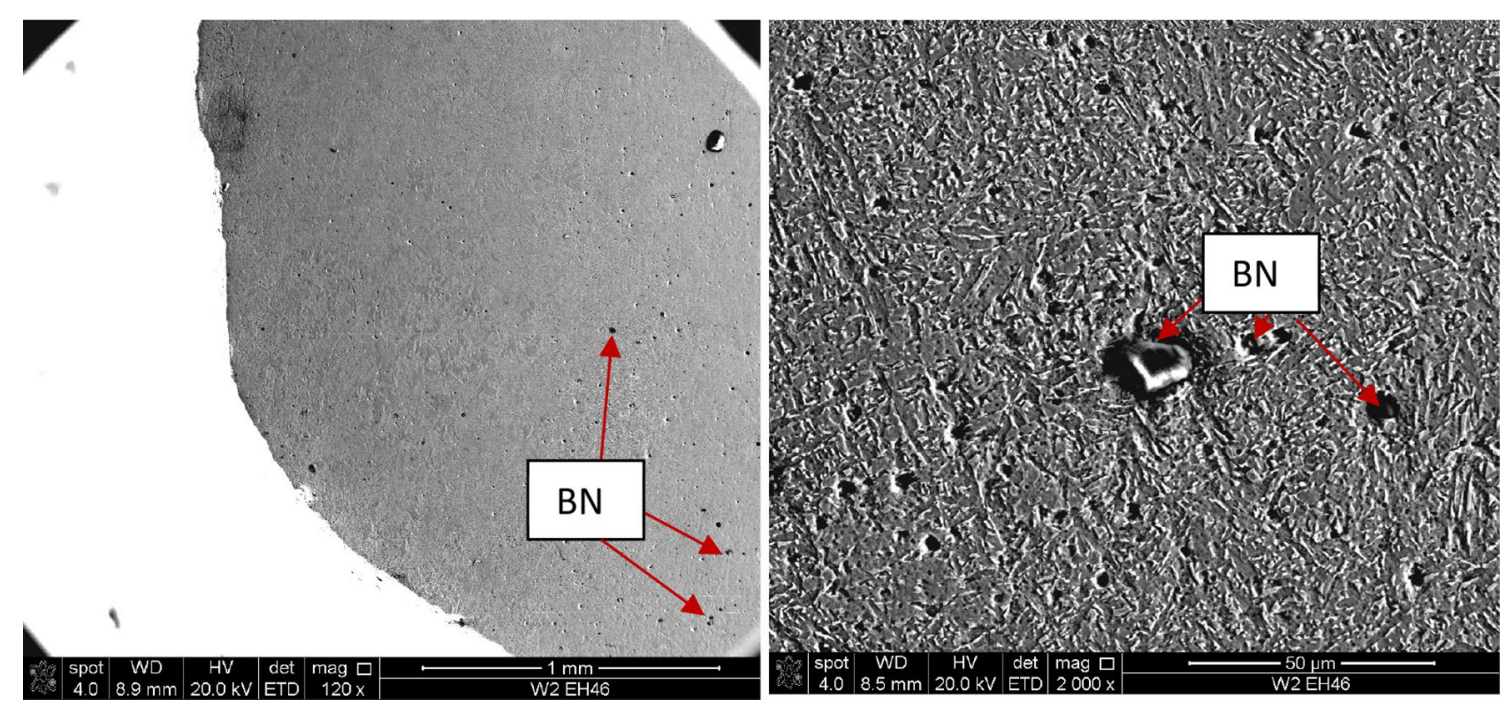

Fig. 9 SEM images of EH46 $\left(\mathrm{W}_{2 \mathrm{E}}\right)$ at plunge/dwell period show BN particles (dark spots) sizes are from 0.5 to $13 \mu \mathrm{m}$. a low magnification and b high magnification
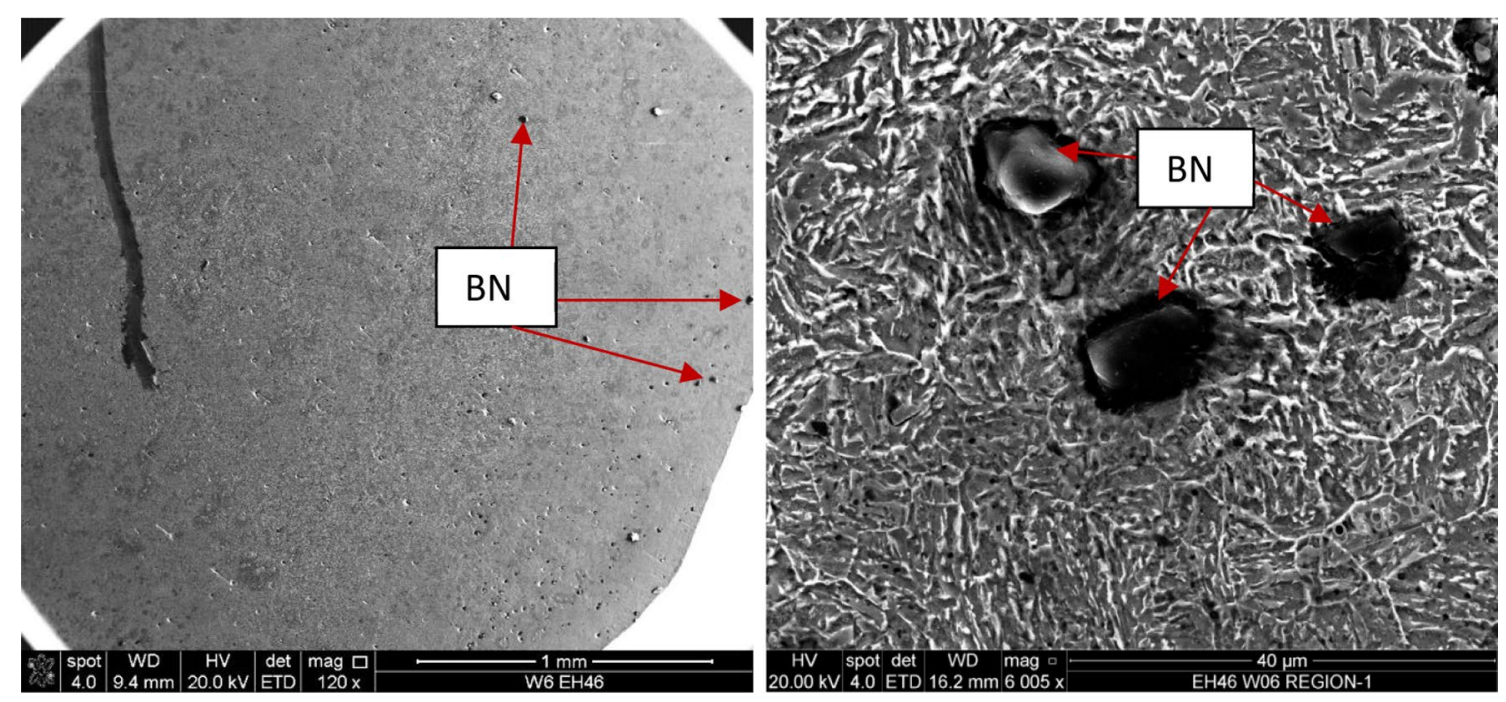

Fig. 10 SEM images of EH46 $\left(\mathrm{W}_{6 \mathrm{E}}\right)$ at plunge/dwell period show BN particles (dark spots) sizes are from 0.5 to $13 \mu \mathrm{m}$. a low magnification and b high magnification

depth the resulted size of TMAZ, IHAZ and OHAZ have also showed differences. Example of that is the difference in the size of TMAZ of W1 $\left(47.46 \mathrm{~mm}^{2}\right)$ and $\mathrm{W} 2\left(67.5 \mathrm{~mm}^{2}\right)$, TMAZ size is increase with the plunge depth increase due to more surface contact area between the tool and workpiece, this in turn can increase the PCBN tool wear. This finding was reported in Table 9 where the calculated percentage (\%) of BN in the shoulder-probe TMAZ of W2 was double than $\mathrm{W} 1$ as the plunge depth in W2 was higher by about $0.4 \mathrm{~mm}$. The effect of plunge depth on the tool wear is also shown in W6 and W7 compared to W3, W4 and W5 which have the same tool rotational speed. W2 which has almost the same plunge depth of W4 and W5 has showed more
$\mathrm{BN} \%$ in the shoulder-probe region, this can be attributed to the higher tool rotational speed the material experienced in W2 (200 RPM) compared to 120 RPM group such as in W4 and W5. High tool rotational speed can result in higher peak temperatures as listed in TCs reading in Table 5 and thus more WRe binder softening is expected [8]. Despite the lower tool rotational speed of W6, its probe side bottom has been showed more BN compared to W2. This can be attributed to the increase in shear stress magnitude on the tool surface as a result of lower temperatures but higher mechanical effect. 

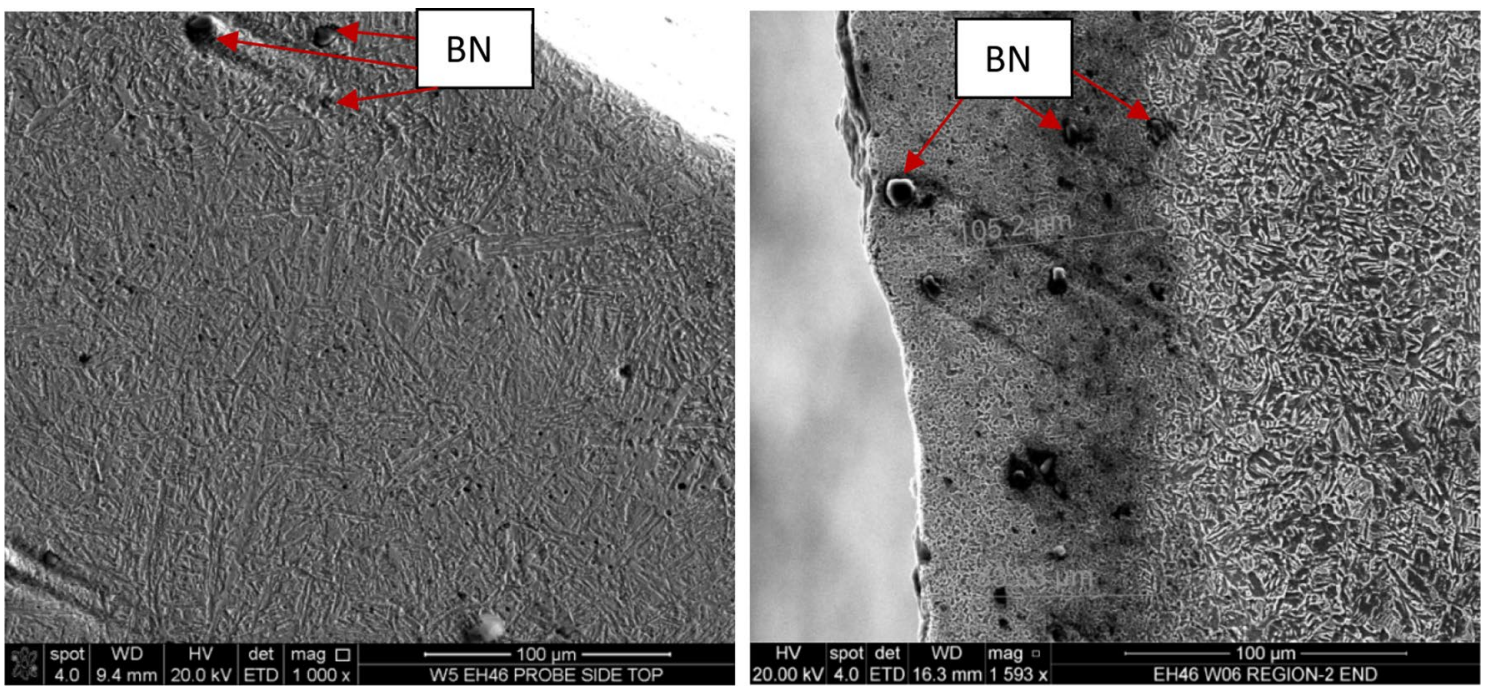

Fig. 11 EH46 at Plunge/dwell period, Probe side bottom (region-2 bottom), a W2 and b W6

Table 9 BN percentage (\%) in EH46 plunge period at shoulder/probe side region, the scanned area is $1 \mathrm{~mm}^{2}$

\begin{tabular}{llllllll}
\hline Weld No. & W1 & W2 & W3 & W4 & W5 & W6 & W7 \\
\hline BN \% & 1.4 & 2.8 & 0.65 & 0.7 & 0.9 & 3.3 & 1.2 \\
\hline
\end{tabular}

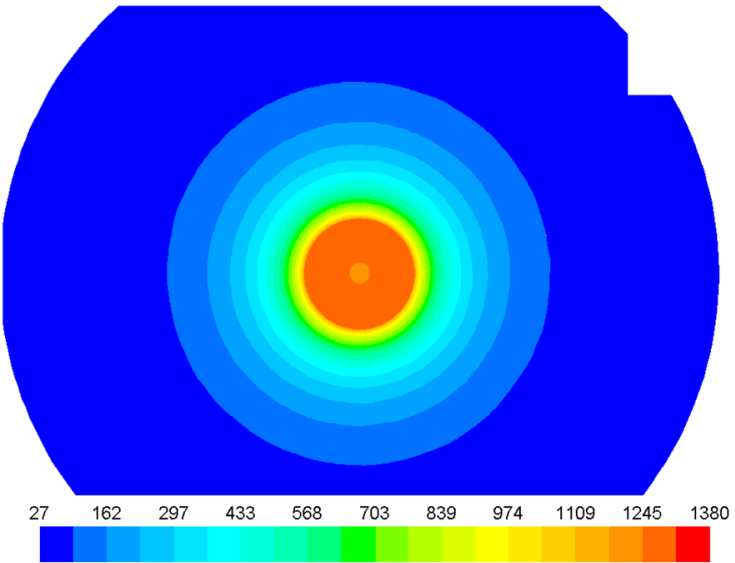

120RPM

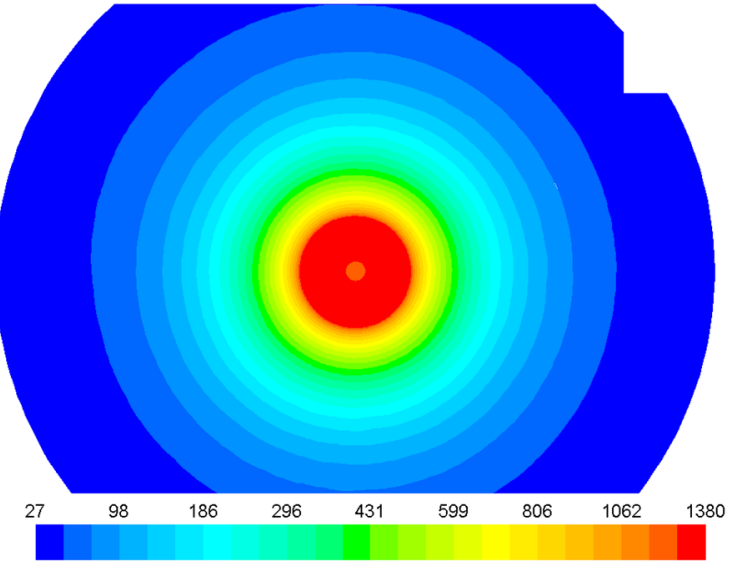

200RPM

Fig. 12 Temperature ${ }^{\circ} \mathrm{C}$ contours at the top surface of EH46 plates at dwell period

\subsection{CFD Model}

\subsubsection{Temperature}

EH46 plunge/dwell cases have been simulated with two sets of tool rotational speeds which are 120 and 200 RPM with a fully sticking conditions and constant plunge depth of $12 \mathrm{~mm}$. Top view of the temperature contours of 120 and 200 RPM dwell cases are shown in Fig. 12. As the plunge/ dwell cases do not include tool traverse speed, a totally symmetrical temperature contours are found in the tool/workpiece contact region. Maximum peaks temperatures were found under the tool shoulder, the HAZ size is increase with tool rotational speed increase due to the increase in thermomechanical action of the tool. Figure 13 shows temperature contours of the tool and workpiece, temperature has showed a decrease towards the plate bottom. This decrease in temperature is coincide with previous work [16, 17] which 


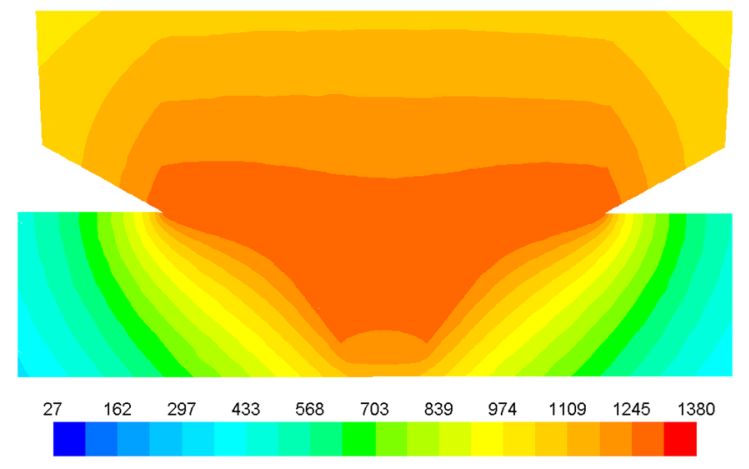

120RPM

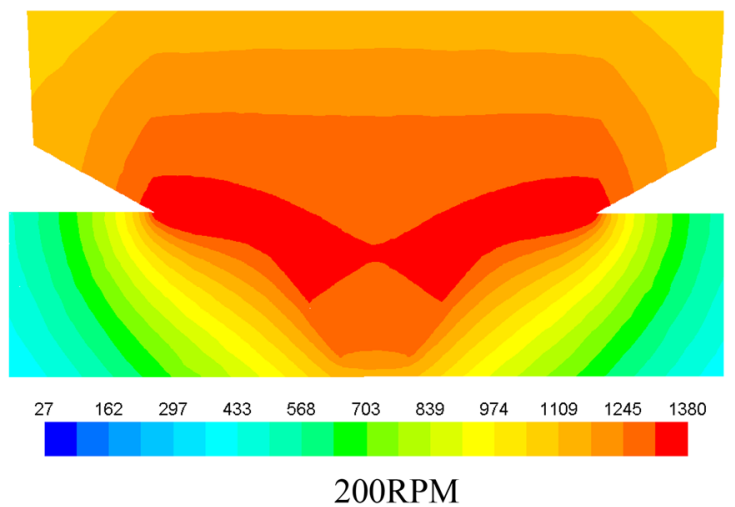

200RPM

Fig. 13 Traverse section shows the temperature ${ }^{\circ} \mathrm{C}$ contour of the PCBN tool and the plate at the dwell period of 120 and $200 \mathrm{RPM}$

showed that maximum temperature were mainly generated from the tool shoulder, whereas, probe side contribution was less and the probe end contribution in heat generation was almost insignificant. Figure 14 shows the temperature distribution around the tool, the CFD results are compared with the maximum peak temperatures of the TC2 and TC5 readings of W1-W7 (see Fig. 3 and Table 5). TCs reading of $\mathrm{W} 1$ and $\mathrm{W} 2$ have been showed a difference from the CFD model of about $80{ }^{\circ} \mathrm{C}$ and attributed to the difference in plunge depth. TCs reading of W3-W7 have showed less difference (about $50{ }^{\circ} \mathrm{C}$ ) from the CFD results. HAZ in Fig. 14 has been determined between the $\mathrm{SZ}$ and a peak temperature of $900{ }^{\circ} \mathrm{C}[31]$.

\subsubsection{Velocity and Strain Rate at The tool/workpiece contact region}

Figure 15 shows the relative velocity distribution in the workpiece which comes from the material affected by the tool rotation. Velocity reaches its maximum value at the tool shoulder periphery and decreases towards the probe middle whereas its value tends to vanish at the probe end. The material velocity in the contact region increases with the increase in the tool rotational speed. $0.237 \mathrm{~m} / \mathrm{s}$ was the maximum value of relative velocity at $120 \mathrm{RPM}$ whereas the relative velocity has increased to $0.396 \mathrm{~m} / \mathrm{s}$ when the tool rotational speed increased to 200 RPM.

Strain rate has showed a similar behaviour of velocity with maximum values of $700 \mathrm{1} / \mathrm{s}$ at the tool periphery (Fig. 16). Strain rate contours also tend to be wider when tool rotational speed increases from 120 to 200 RPM due to more material has affected by the tool thermo-mechanical action, this result is in agreement with the findings found in [32] [33]. The strain rate also shows a decrease towards the workpiece bottom and its values tend to vanish at the probe end centre as shown in Fig. 16.

\subsubsection{Viscosity of the Workpiece at the Tool/Workpiece Contact Region}

Viscosity contours of 120 and 200 RPM plunge/dwell are shown in Fig. 18. The shear layer size increases with the increase of tool rotational speed due to more heat has been generated in the material in contact with the FSW tool; this in turn encouraged the materials layers to rotate with a specific velocity. Viscosity values has showed a significant decrease under tool shoulder, the region between shoulder and probe has showed the maximum TMAZ size as a results of the thermo-mechanical combination between the shoulder and the probe side. This finding is coincide with the IFM of W1-W7 (Fig. 8) as all the macrographs have been showed that TMAZ at the shoulder-probe is the most affected region by the tool. The probe end did not show significant decrease in the value of viscosity that can enable the material in contact to rotate despite the high temperature which reached to $1000^{\circ} \mathrm{C}$ (Fig. 13). As it is known, the viscosity is inversely proportional to temperature and strain rate which its value was too low at probe end. The experiments of IFM of EH46 W1-W7 shown in Fig. 8 are coincide with the CFD findings in Fig. 17, all the macrographs have showed that at probe end the material is only experienced heating without stirring. This finding is in agreement with Schmidt and Hattle work which reported that during the FSW process, probe end represent less than $3 \%$ from the heat generated in the weld $[16,17]$. The cut-off value of viscosity after which no material flow occurs as shown in Fig. 17 is equal to $9.6 \times 10^{6} \mathrm{~Pa} \mathrm{~s}$ which is in agreement with previous work on steel extrusion [15].

\subsubsection{Tool Surface Temperature and Shear Stress}

Temperature distribution on the tool surface as shown in Fig. 18 for 120 and 200 RPM are symmetrical with maximum temperatures located at the tool shoulder periphery. Temperature is decrease towards the probe side and it 


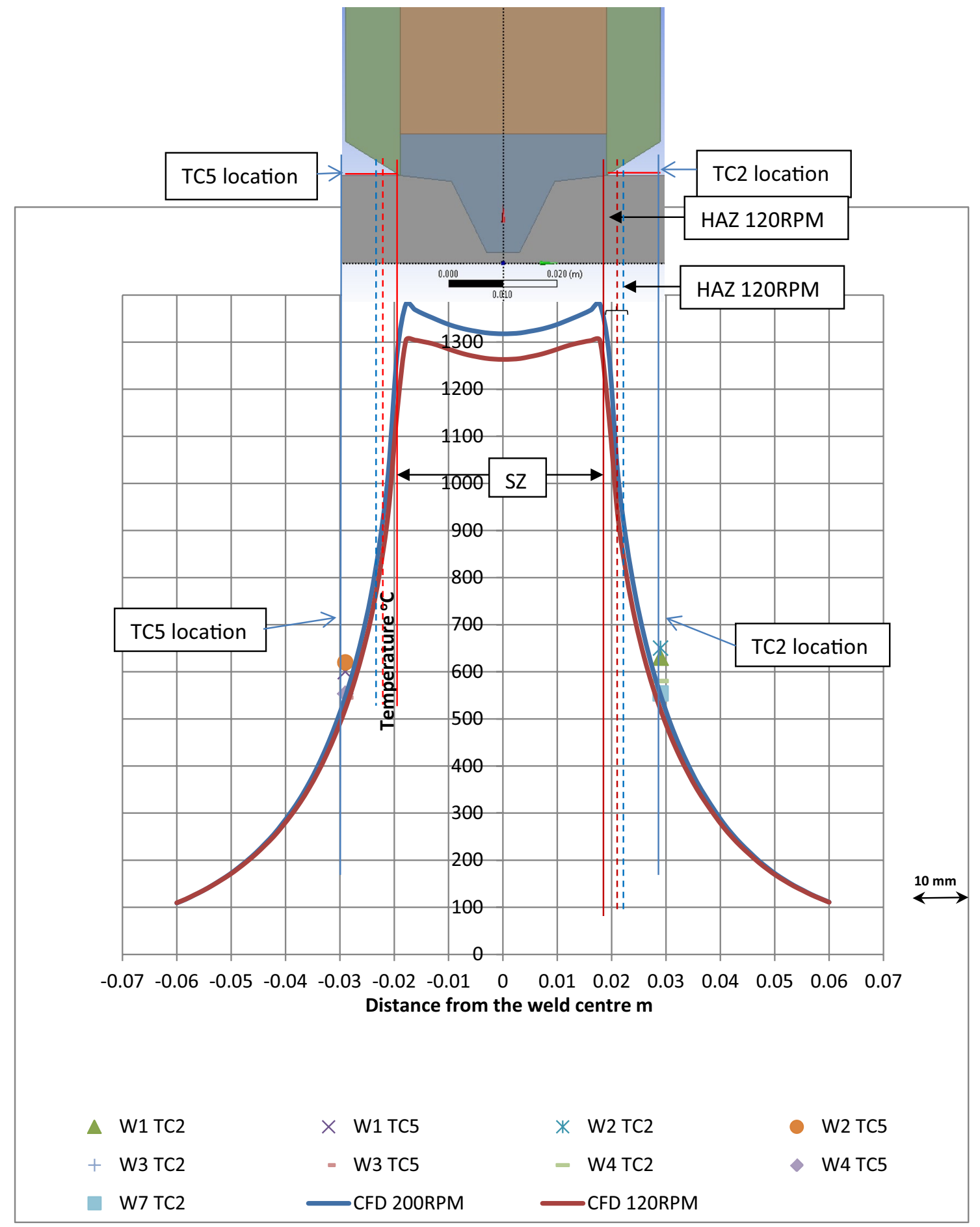

Fig. 14 CFD results show the temperature distribution along the top centre of the FSW EH46 at dwell period

reaches the minimum value at the probe end. Binder softening is highly expected in the high tool rotational speeds (200 RPM group) especially at tool shoulder periphery which in turn can cause; with the aid of mechanical action; a significant tool wear $[8,34]$.
Shear stress on the tool surface as shown in Fig. 19 for 120 and 200 RPM groups are symmetrical with maximum shear stress located at the bottom of probe side. Shear stress is increase with rotational speed decrease as a result of higher viscosity of the workpiece in contact with the FSW tool. The bottom of the probe side of 120 RPM group has 


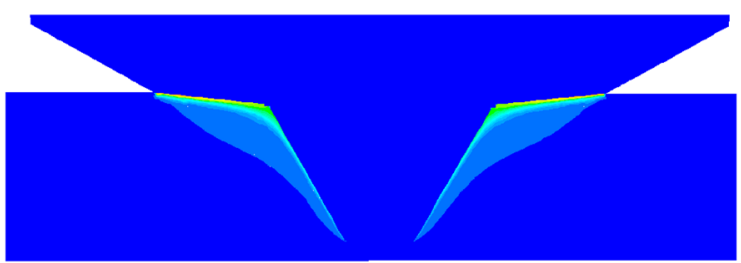

$\begin{array}{lllllllllll}0.000 & 0.024 & 0.047 & 0.071 & 0.095 & 0.118 & 0.142 & 0.166 & 0.189 & 0.213 & 0.237\end{array}$ 120RPM

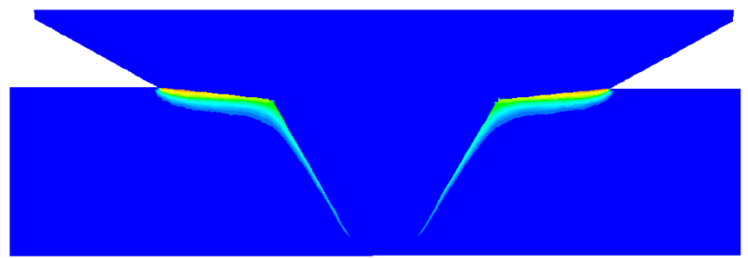

$\begin{array}{lllllllllll}0.000 & 0.040 & 0.079 & 0.119 & 0.158 & 0.198 & 0.237 & 0.277 & 0.317 & 0.356 & 0.396\end{array}$ 200RPM

Fig. 15 Traverse section shows the velocity contours (m/s) in the tool/workpiece contact region at the dwell period of 120 and 200 RPM

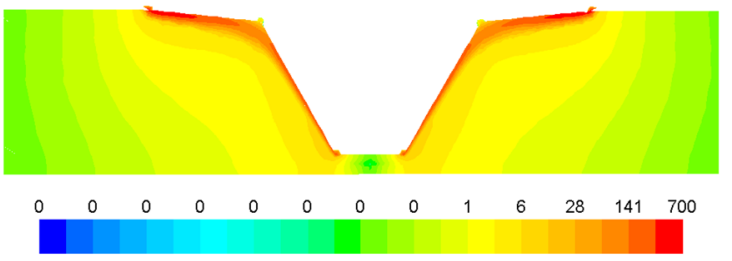

120RPM



200RPM

Fig. 16 Traverse section shows the strain rate contours (1/s) in the tool/workpiece contact region at the dwell period of 120 and $200 \mathrm{RPM}$

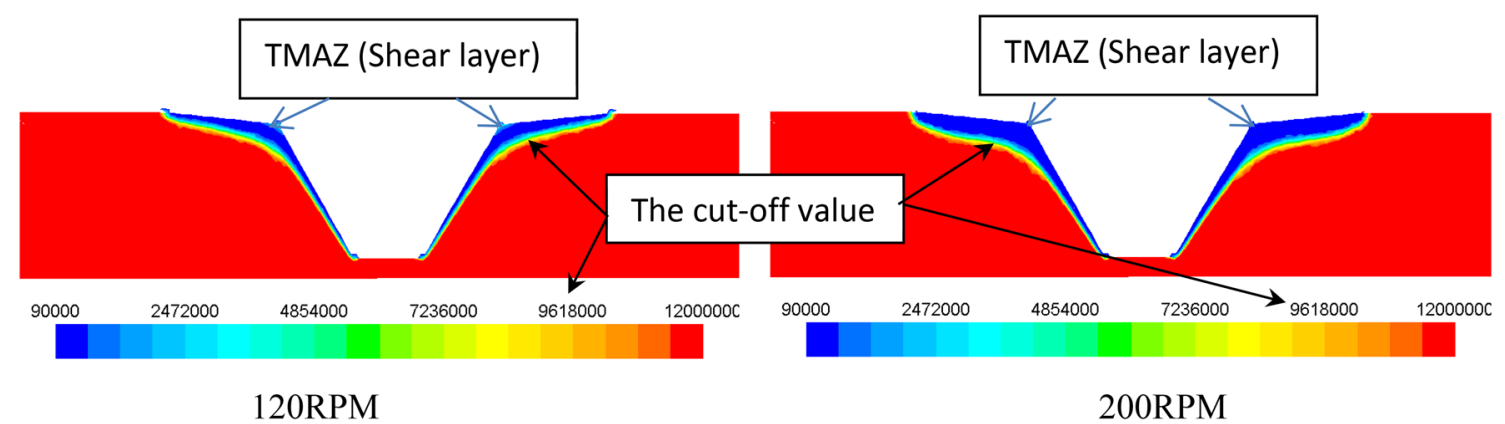

Fig. 17 Traverse section shows the viscosity contours (Pa s) in the tool/workpiece contact region at the dwell period of 120 and 200 RPM

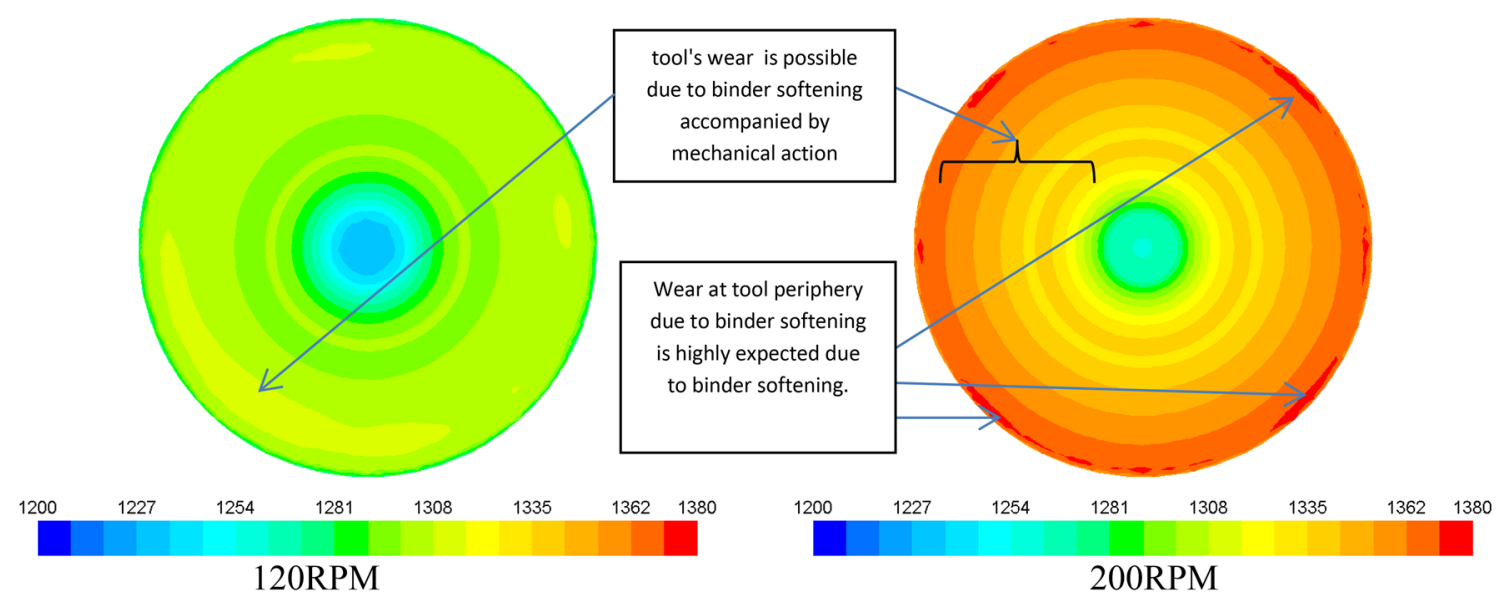

Fig. 18 Tool surface temperature at 120 and 200 RPM (dwell period) 


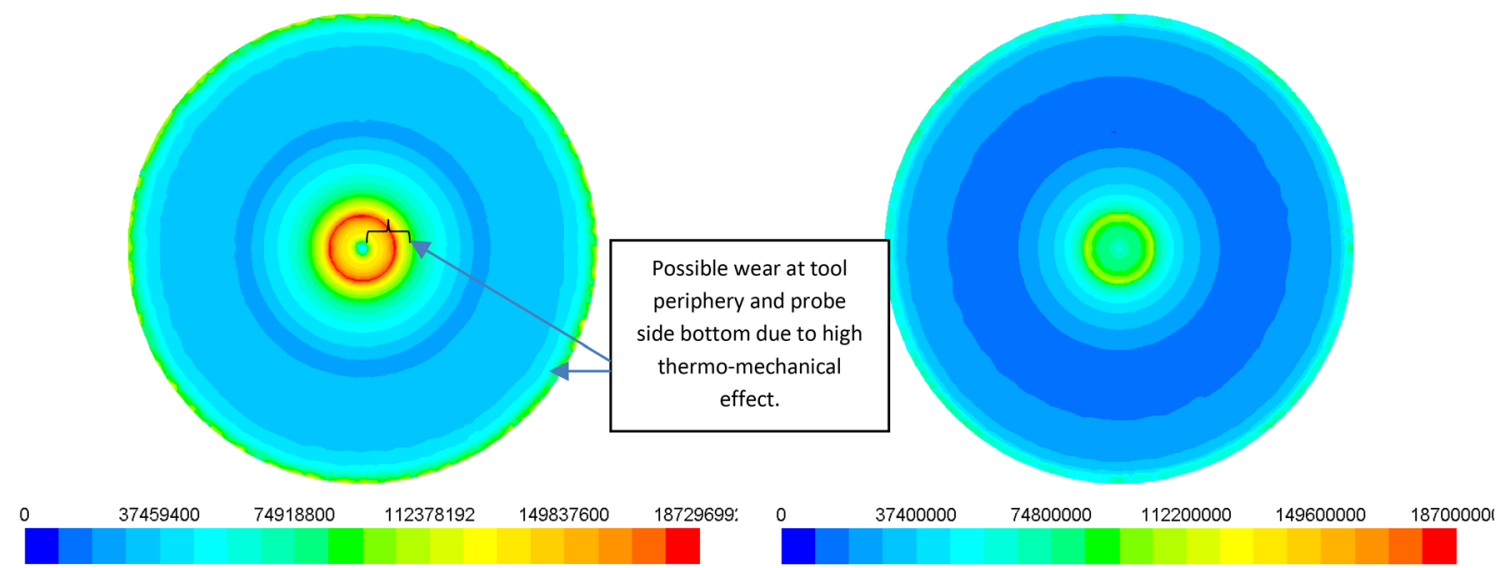

120RPM

200RPM

Fig. 19 Tool surface shear stress (Pa) at 120 and 200 RPM (dwell period)

showed the maximum shear stress value and thus the tool wear at that location is expected. The SEM image of probe side bottom of EH46 probe end (120 RPM) as shown in Fig. $11 \mathrm{~b}$ supports the finding of the CFD regarding the tool wear as a result of shear stress increase. Shear stress is also high at tool shoulder periphery of 120 RPM and also probe side bottom of 200 RPM as shown in Fig. 19.

The high temperature at tool shoulder of 200 RPM group and high shear stress (reach to $180 \mathrm{MPa}$ ) at the tool shoulder periphery of 120 RPM group can significantly cause wear on the tool surface. Experiments including SEM images of EH46 W1-W7 support the findings of the CFD as shown in Figs. 9, 10 and also in Table 9 where BN particles is exist in the region of shoulder-probe as a result of the combination of binder softening and shear stress at the FSW tool surface.

\section{Conclusion}

In conclusion, the wear issue of PCBN FSW tool has been investigated experimentally and numerically during the plunge/dwell period. The wear of the tool has been attributed to two main reasons; first one is the WRe binder softening when the peak temperature exceeds $1200{ }^{\circ} \mathrm{C}$. The second one is the increase in shear stress magnitude to $180 \mathrm{MPa}$ especially at probe side bottom as a result of workpiece material resistance coming from low temperatures. Tool shoulder periphery and probe side bottom were found to be the most vulnerable parts on the tool that exposed to wear issues. From the CFD modelling, the maximum peak temperature that can cause binder softening was found at the tool shoulder periphery whereas the maximum shear stress was found at probe side bottom. The CFD model was in agreement with the SEM result which has showed a high $\mathrm{BN}$ existence in the region of contact with the tool probe/ shoulder region. High amount of $\mathrm{BN}$ was found at the shoulder/workpiece contact region when rotational speed increase and the maximum was in the probe side bottom/workpiece contact region when tool rotational speed decrease.

Acknowledgements The authors would like to thank the ministry of higher education Iraq for funding this study. Thanks for TWI company for providing data and samples.

Open Access This article is distributed under the terms of the Creative Commons Attribution 4.0 International License (http://creativeco mmons.org/licenses/by/4.0/), which permits unrestricted use, distribution, and reproduction in any medium, provided you give appropriate credit to the original author(s) and the source, provide a link to the Creative Commons license, and indicate if changes were made.

\section{References}

1. R.S. Mishra, Z.Y. Ma, Friction stir welding and processing. Mater. Sci. Eng. R. Rep. 50(1-2), 1-78 (2005)

2. Megastir, Friction stir welding of high melting temperature materials, (2013). http://megastir.com/products/tools/fsw_tool.aspxpdf

3. R. Rai, A. De, H.K.D.H. Bhadeshia, T. DebRoy, Review: friction stir welding tools. Sci. Technol. Weld. Join. 16(4), 325-342 (2011)

4. J. M. Seaman, B. Thompson, Challenges of Friction Stir Welding of Thick-Section Steel, in Proceedings of the Twenty-first (2011) International Offshore and Polar Engineering Conference, Maui, Hawaii, USA, June 19-24, (2011)

5. P.J. Konkol, M.F. Mruczek, Comparison of friction stir weldments and submerged arc Weldments in HSLA-65 steel. Suppl Weld J 86, 187-195 (2007)

6. J. Perrett, J Martin, J Peterson, R Steel, S Packer, Friction stir welding of industrial steels, in Paper presented at TMS Annual Meeting 2011 (San Diego, CA, USA, 2011) 
7. C.D. Sorensen, T.W. Nelson, Friction Stir Welding of Ferrous and Nickel Alloys, (2007 ASM International. P113

8. M.L. Ramalingam, D.L. Jacobson, Elwvated temperature softening of progressively annealed and sintered W-Re alloys. J. Less Common Met. 123, 153-167 (1986)

9. S. Parker, T. Nelson, C. Sorensen, R. Steel, M. Matsunaga, Tool and equipment requirements for friction stir welding ferrous and other high melting temperature alloys, in Proceedings of Fourth International Symposium on Friction Stir Welding, 14-16 May 2003 (TWI, Park City, UT)

10. S.H.C. Park, Y.S. Sato, H. Kokawa, K. Okamoto, S. Hirano, M. Inagaki, Boride formation induced by pcBN tool wear in frictionstir-welded stainless steels. Metall. Mater. Trans. A 40, 625 (2009)

11. Y.N. Zhang, X. Cao, S. Larose, P. Wanjara, Review of tools for friction stir welding and processing. Can. Metall. Q. 51(3), 250 (2012)

12. J. Kim, S. Lee, H. Kwun, K. Shin, C. Kang, SIMS evaluation of poly crystal boron nitride tool effect in thermo-mechanically affected zone of friction stir weld steels. Met. Mater. Int. 20(6), 1067-1071 (2014)

13. M.P. Miles, C.S. Ridges, Y. Hovanski, J. Peterson, M.L. Santella, R. Steel, Impact of tool wear on joint strength in friction stir spot welding of DP 980 steel. Sci. Technol. Weld. Join. 16(7), 642-647 (2011)

14. R. Nandan, G.G. Roy, T.J. Lienert, T. Debroy, Three-dimensional heat and material flow during friction stir welding of mild steel. Acta Mater. 55(3), 883-895 (2007)

15. H.B. Schmidt, J. Hattel, Modelling heat flow around tool probe in friction stir welding. Sci. Technol. Weld. Join. 10(2), 176-186 (2005)

16. H.B. Schmidt, J. Hattel, Heat source models in simulation of heat flow in friction stir welding. Int. J. Offshore Polar Eng. 14(4), 296-304 (2004)

17. H. Atharifar, D. Lin, R. Kovacevic, Numerical and experimental investigations on the loads carried by the tool during friction stir welding. J. Mater. Eng. Perform. 18(4), 339-350 (2009)

18. C. Cox, D. Lammlein, A. Strauss, G. Cook, Modelling the control of an elevated tool temperature and the affects on axial force during friction stir welding. Mater. Manuf. Process. 25, 1278-1282 (2010)

19. ANSYS company, 1978, Workbench help viewer manual (USA, 2016). Accessed Aug 2016

20. A.R. Darvazi, M. Iranmanesh, Thermal modeling of friction stir welding of stainless steel 304L. Int. J. Adv. Manuf. Technol. 75(9-12), 1299-1307 (2014)
21. A.I. Toumpis, A. Gallawi, L. Arbaoui, N. Poletz, Thermo-mechanical deformation behaviour of DH36 steel during friction stir welding by experimental validation and modelling. Sci. Technol. Weld. Join. 19(8), 653-663 (2014)

22. Subrata Pal, M.P. Phaniraj, Determination of heat partition between tool and workpiece during FSW of SS304 using 3D CFD modelling. J. Mater. Process. Technol. 222, 280-286 (2015)

23. B.L. Theodore, F.P. Incropera, P. DeWitt David, A.S. Lavine, Fundamentals of Heat and Mass Transfer, 7th edn. (Wiley, London, 2011)

24. D. Micallef, D. Camilleri, A. Toumpis, A. Galloway, L. Arbaoui, Local heat generation and material flow in friction stir welding of mild steel assemblies. J. Mater. Des. Appl. 230(2), 586-602 (2016)

25. M.Z.H. Khandkar, J.A. Khan, A.P. Reynolds, Prediction of temperature distribution and thermal history during friction stir welding: input torque based model. Sci. Technol. Weld. Join. 8(3), 165-174 (2003)

26. A.F. Hasan, C.J. Bennett, P.H. Shipway, A numerical comparison of the flow behaviour in Friction Stir Welding (FSW) using unworn and worn tool geometries. Mater. Des. 87, 1037-1046 (2015)

27. J. Lenard, M. Pietrzyk, L. Cser, Mathematical and Physical Simulation of the Properties of Hot Rolled Products (Elsevier, Amsterdam, 1999), pp. 1-10

28. Megastir, Friction Stir Welding of High Melting Temperature Materials (2013) http://megastir.com/products/tools/fsw_tool. aspxpdf

29. R. Endo, M. Shima, M. Susa, Thermal-conductivity measurements and predictions for $\mathrm{Ni}-\mathrm{Cr}$ solid solution alloys. Int. J. Thermophys. 31, 1991-2003 (2010)

30. E.S. Leonard, Light Microscopy of Carbon Steel (ASM International, USA, 1999)

31. Y. Morisada et al., Three-dimensional visualization of material flow during friction stir welding of steel and aluminum. J. Mater. Eng. Perform. 23(11), 4143-4147 (2014)

32. K.Y. Yang, H. Dong, S. Kou, Liquation tendency and liquid-film formation in friction stir spot welding. Weld. J. 87, 202-211 (2008)

33. R. Rai, A. De, H.K.D.H. Bhadeshia, T. DebRoy, Review: friction stir welding tools. Sci. Technol. Weld. Join. 16(4), 325-342 (2011)

34. P.J. Konkol, M.F. Mruczek, Comparison of friction stir weldments and submerged arc weldments in HSLA-65 steel. Suppl. Weld. J. 86, 187-195 (2007) 